\title{
Procjena rizika od pada: pregled skala za evaluaciju rizika
}

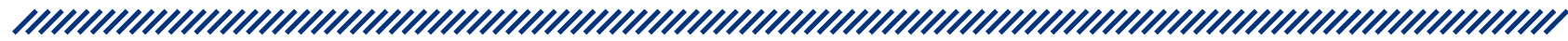

1 Roberto Licul

1 Tatjana Matteoni

1 Martina Močenić

1 Opća bolnica Pula, Pula
Ključne riječi: sigurnost pacijenta, procjena rizika, pad u bolničkoj ustanovi, kvaliteta u zdravstvenoj njezi

Datum primitka: 03.11.2016.

Datum prihvaćanja: 01.06.2017.

DOI: $10.24141 / 3 / 1 / 8$

Adresa za dopisivanje:

Roberto Licul

Odjel traumatologije i ortopedije Službe za kirurške bolesti

Opća bolnica Pula

Aldo Negri 6, 52100 Pula

E-pošta: roberto.licul@obpula.hr

Tel: +38552376302

\section{UVOD}

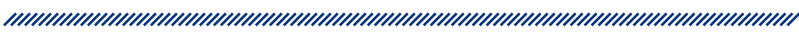

Padovi hospitaliziranih pacijenata spadaju u skupinu neželjenih događaja u zdravstvenim ustanovama te su pokazatelj sigurnosti pacijenata u bolnici, što je u konačnici najpouzdaniji indikator kvalitete zdravstvenog sustava. Prema podacima Agencije za kvalitetu i akreditaciju u zdravstvu i socijalnoj skrbi (AAZ), u 2014. godini zbirna stopa incidencije iznosila je 45,4 pada na 100000 bolesničkih dana. ${ }^{1}$ Treba uzeti u obzir da su ti podaci nepotpuni s obzirom na to da je ispravno izvješće dostavilo svega 16 od 62 hrvatskih bolničkih zdravstvenih ustanova. $U$ razvijenim zemljama stopa incidencije iznosi 1,7 do 25 padova na 1000 bolesničkih dana² (broj 
padova ovisi o tipu bolnice i populaciji pacijenata), a otprilike $30 \%$ padova završava ozljedom, od čega $4 \%$ do $6 \%$ teškim ozljedama, uključujući i smrt. ${ }^{3}$ Osim psihofizičkih poteškoća koje pad uzrokuje bolesniku, kod takvih se pacijenata produžuje boravak u bolnici i povećavaju troškovi liječenja, ${ }^{4}$ a padovi predstavljaju i potencijalni pravni problem. ${ }^{5}$ Podaci AAZ-a ${ }^{1}$ pokazuju da je u Hrvatskoj izražen trend rasta incidencije pada s dobi, što je u skladu s pokazateljima iz drugih zemalja, dok razlika u broju padova između muškarca i žena nije statistički značajna (slika 1 ).

Prema statističkim podacima britanske Agencije za sigurnost pacijenata (National Patient Safety Agency), u bolnici sa 800 kreveta tjedno se može očekivati 24 , a godišnje oko 1260 padova pacijenata. ${ }^{6}$ Iz izvješća Agencije iznalazi se kako je pad u bolnici najučestaliji oblik prijavljenoga neželjenog događaja u zdravstvenim ustanovama.

U stručnoj literaturi mnogo je pažnje posvećeno istraživanju uzroka padova u stacionarnim ustanovama te se oni u pravilu mogu podijeliti u dvije kategorije: unutarnje (intrinzične) i vanjske (ekstrinzične). Unutarnji faktori, koji se ponajprije odnose na pacijenta, uključuju stariju životnu dob, kronične bolesti, slabost muskulature, poteškoće u kretanju i narušeno mentalno zdravlje ${ }^{7}$. Vanjski, odnosno okolinski faktori odnose se na prepreke pri kretanju, neodgovarajuće osvjetljenje, sklizave površine i slično. Uz sve navedeno, padovima pridonose boravak u nepoznatom prostoru (bolesnička soba), produženo ležanje u krevetu, operacijski zahvati i utjecaj anestezije, postavljanje različitih drenova i katetera te primjena određenih skupina lijekova (anksiolitici, analgetici). ${ }^{8}$

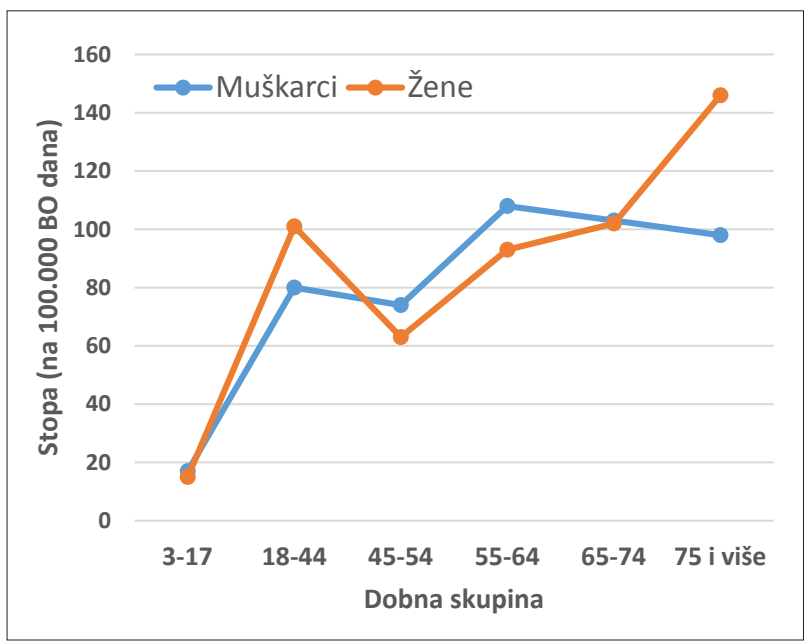

Slika 1. Zbirne stope incidencije pada po dobi i spolu 2014. godine (prilagođeno prema podacima $\mathrm{AZZ}-\mathrm{a}^{1}$ )
U prevenciju pada bolesnika moraju biti uključeni svi zdravstveni djelatnici, a posebice medicinske sestre / medicinski tehničari, liječnici i fizioterapeuti. S obzirom na to da medicinska sestra provodi najveći dio vremena u direktnom kontaktu s pacijentom, njezina je dužnost procijeniti rizik od pada te poduzeti odgovarajuće mjere za njegovu prevenciju u skladu s njezinim kompetencijama i resursima koji su dostupni u zdravstvenoj ustanovi. Potrebno je odmah pri prijmu izvršiti procjenu rizika od pada te ga kasnije (najbolje svakodnevno) evaluirati ovisno o tijeku liječenja, promjenama i ponašanju pacijenta u bolničkoj ustanovi. Najvažniji alat koji medicinska sestra posjeduje za procjenu pada jest njezino iskustvo i znanje.

\section{SKALE ZA PROCJENU PADA}

Idealna ljestvica za procjenu rizika pada trebala bi biti jednostavna za upotrebu, precizna, ne iziskivati previše vremena za ispunjavanje te biti lako uklopiva u kliničku praksu bez dodatnog opterećivanja već preopterećenog osoblja. ${ }^{9}$

Kod evaluacije učinkovitosti skala procjenjuju se četiri elementa ${ }^{10}$ : osjetljivost (sensitivity), specifičnost (specificity), pozitivna prediktivna vrijednost - PPV (positive predictive value) te negativna prediktivna vrijednost - NPV (negative predictive value). Osjetljivost označava proporciju pacijenata koji su pali i onih kod kojih je ispravno procijenjen visok rizik od pada. Specifičnost jest proporcija onih koji nisu pali te su ispravno procijenjeni niskorizičnima za pad. Pozitivna prediktivna vrijednost označava proporciju pacijenata koji su pali i kod kojih je ispravno procijenjen visok rizik za pad, od ukupno svih kod kojih je procijenjen visok rizik za pad. Negativna prediktivna vrijednost jest proporcija osoba koje nisu pale i kod kojih je ispravno procijenjen nizak rizik za pad, od ukupno svih kod kojih je procijenjen nizak rizik za pad.

Poželjno je da skala za procjenu rizika od pada ima što veću osjetljivost i specifičnost. Zbog niske osjetljivosti skale određen broj pacijenata s visokim rizikom za pad može biti neprepoznat, a zbog niske specifičnosti veći se broj pacijenata nepotrebno procjenjuje rizičnim, što može rezultirati pretjeranim preventivnim mjerama i bespotrebnim trošenjem materijalnih i kadrovskih resursa. 
Poticaj za izradu alata za procjenu rizika od pada javio se početkom osamdesetih godina 20. stoljeća, nakon što je epidemiološkim studijama dokazano da padovi hospitaliziranih osoba mogu biti spriječeni.

U ovom radu bit će prikazane četiri skale za procjenu rizika od pada koje se najučestalije spominju u stručnoj literaturi, i to: Morseova skala ${ }^{11}$, skala STRATIFY' ${ }^{12}$, skala Hendrich II. ${ }^{13}$ te skala koju je osmislilo osoblje baltimorske bolnice Johns Hopkins ${ }^{14}$. Osim navedenih, u literatu-

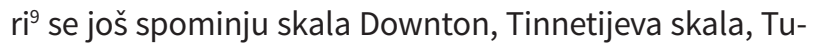
llamoreova skala i druge. Svaka od skala ima određene prednosti i nedostatke, a njihova je primjena ponajprije namijenjena upotrebi u zdravstvenim ustanovama među odraslom populacijom. Za procjenu pada među pedijatrijskom populacijom primjenjuju se skala GRAF PIF, skala CHAMPS, skala Humpty Dumpty te skala Cummings ${ }^{15}$.

\subsection{MORSEOVA SKALA}

Jedna od najčešće korištenih skala za procjenu pada jest Morseova skala ${ }^{11}$ (Morse Fall Scale - MSF) ${ }^{*}$, koja je ujedno jedna od najčešće istraživanih u literaturi. Skala se temelji na šest osnovnih elemenata na temelju kojih se procjenjuje rizik od pada: prethodni padovi, druge medicinske dijagnoze, pomagala pri kretanju, primjena infuzija, stav/premještanje te mentalni status. Svaka se od navedenih kategorija boduje te se ovisno o dobivenom rezultatu (maksimalni je broj bodova 125) pacijent svrstava u jednu od tri skupine: 0 do 24 bodova - nizak rizik, 25 do 44 bodova - umjeren rizik te više od 45 bodova - visok rizik.

Ova skala nastala je 1985. godine kao rezultat prospektivnog istraživanja čiji je cilj bio identificirati i procijeniti rizik od pada kod 100 pacijenata koji u svojoj anamnezi imaju zabilježen pad, dok je u kontrolnoj skupini bilo 100 nasumično izabranih pacijenata koji nisu imali zabilježen pad. Pacijenta se procjenjuje tijekom razgovora i bilježe se njegovi odgovori na šest pitanja iz skale. Procijenjeno je vrijeme trajanja ispunjavanja skale manje od tri minute.

Prema istraživanju iz 1999. godine, osjetljivost Morseove skale iznosi $72 \%$, specifičnost $51 \%$, PPV $38 \%$, a NPV $81 \% .{ }^{16}$ Slični rezultati dobiveni su tijekom istraživanja provedenog 2006. godine u jednoj švicarskoj bolnici, prema kojem osjetljivost skale iznosi $74,5 \%$, specifičnost $65,8 \%$, PPV $23,2 \%$, a NPV $94,9 \% .{ }^{17}$ Tada je uočen

Skala je na engleskom jeziku slobodno dostupna na internetu, npr. https://consultgeri.org/try-this/general-assessment/issue-8.pdf velik postotak pacijenata koji su procijenjeni visokorizičnima za pad, a kod kojih nije došlo do pada (75,9 do $87,5 \%)$.

\subsection{SKALA STRATIFY}

Skala STRATIFY (St Thomas's Risk Assessment Tool in Falling Elderly In-Patients) ** predstavljena je 1997 godine. ${ }^{12}$ Razvijana je kroz tri faze provođene $u$ dvije bolnice u Velikoj Britaniji: prve dvije faze provedene su u bolnici St. Thomas's, a treća u bolnici Kent and Canterbury.

Procjena se temelji na pet osnovnih pitanja koja se boduju po jedan bod ako je odgovor pozitivan odnosno ne boduju ako je odgovor negativan. Prvo pitanje usmjereno je na eventualni nedavni pad, dok se kroz drugo, treće i četvrto pitanje ispituju (akutne) promjene koje bi mogle utjecati na povećani rizik od pada, poput agitiranosti (uznemirenosti) pacijenta, slabovidnosti koja utječe na svakodnevno funkcioniranje te potrebe za češćim vršenjem nužde (primjena diuretika, funkcionalna inkontinencija, nikturija i slično). Posljednjim pitanjem evaluira se pacijentova mogućnost samostalnog premještanja iz kreveta u stolac te njegova pokretljivost. Odabirom odgovarajućih ponuđenih opcija te njihovim zbrajanjem dobiva se rezultat koji, ako iznosi 3 ili 4, predstavlja faktor rizika za pad. Maksimalan zbroj bodova iznosi 5 te se pacijent ovisno o dobivenom rezultatu svrstava $u$ jednu od sljedećih kategorija: $0=$ nizak rizik, 1 = umjeren rizik te $2 \mathrm{i}$ više = visok rizik od pada.

Skala je jednostavna za upotrebu te procijenjeno vrijeme za ispunjavanje iznosi nekoliko minuta. Osjetljivost i specifičnost skale ispitivana je u nekoliko različitih studija provedenih u bolnicama u Velikoj Britaniji, Kanadi, Italiji i Australiji. ${ }^{18}$ Usporedbom tih studija došlo se do sljedećih rezultata: osjetljivost iznosi od 67,2 do $93 \%$, specifičnost od $51,2 \%$ do $87,7 \%$, PPV od $23,1 \%$ do $62,3 \%$ te NPV od $86,5 \%$ do $98,3 \%{ }^{19}$

Osim originalne, postoji i nekoliko modificiranih verzija ove skale ${ }^{20}$, poput Ontario Modified STRATIFY (Sydney Scoring) koja donosi detaljniju evaluaciju rizika od pada (primjenjuje se i drugačiji bodovni sustav), zatim verzija Bendigo (namijenjena za upotrebu u stacionarnim ustanovama) te the Northern Hospital Modified STRATIFY, koja u obzir između ostalog uzima i dob pacijenta.

Skala je na engleskom jeziku slobodno dostupna na internetu, npr. https://www.ahrq.gov/professionals/systems/hospital/fallpxtoolkit/fallpxtk-tool3h.html te na hrvatskom jeziku u sklopu dokumenta dostupnog na http://neuron.mefst.hr/docs/katedre/znanstvena_metodologija/OZS/Sestrinska_lista.pdf 


\subsection{SKALA HENDRICH II}

Skala Hendrich II. (Hendrich II Fall Risk Model) ${ }^{13}$ nastala je 2003. godine kao rezultat istraživanja medicinske sestre Ann Hendrich o uzrocima koji pridonose povećanom riziku od pada pacijenata u bolničkom okruženju. Skala se temelji na sedam osnovnih rizičnih faktora koji se boduju prema bodovima iz tablice ako je kod pacijenta prisutan određeni faktor rizika**. Ako određeni faktor rizika kod pacijenta nije prisutan, ta se kategorija boduje nulom. ${ }^{21}$ Posebnost ove skale čini test ustajanja i hodanja (Get Up \& Go Test) koji je njezin sastavni dio i kojim se na jednostavan način boduje pacijentova sposobnost ustajanja, čime se procjenjuje njegova stabilnost. Također, posebnost ove skale leži u tome što se u okviru procjene rizika od pada boduje i primjena antiepileptika i benzodiazepina - lijekova koji utječu na središnji živčani sustav te mogu pridonijeti pojavi vrtoglavice, konfuzije, dezorijentiranosti i mišićnoj slabosti. ${ }^{21-23}$ Također, dodatno se boduju pacijenti muškog spola, koji su prema istraživanju autorice skale procijenjeni rizičnijima za pad u odnosu na osobe ženskog spola. ${ }^{24}$

Najveći mogući zbroj bodova na ovoj skali iznosi 16, a svi pacijenti koji imaju 5 ili više bodova svrstavaju se u skupinu povećanog rizika od pada. Što je broj bodova veći, nadzor nad pacijentima mora biti pomniji, a preventivne mjere opsežnije.

Prema dosad provedenim istraživanjima, osjetljivost skale kreće se od 70 do $86 \%$, specifičnost od 43 do $74 \%$, PPV od 2 do $11 \%$ te NPV od 95 do $97 \%$. ${ }^{24-26}$

\subsection{SKALA BOLNICE JOHNS HOPKINS}

Jedna od najrecentnijih skala za procjenu pada, čija je učinkovitost potvrđena istraživanjima objavljenima $u$ stručnim i znanstvenim radovima, jest skala baltimorske bolnice Johns Hopkins (The Johns Hopkins Fall Risk Assessment Tool) ${ }^{14}$ iz 2005. godine. Ovu skalu ${ }^{\star \star \star *}$ osmislile su medicinske sestre bolnice, a u obzir uzima sedam osnovnih faktora rizika: pacijentovu dob, povijest padova, fiziološke funkcije (mokrenje i defekaciju), upotrebu lijekova koji povećavaju rizik od pada, upotrebu opreme za bolesničku skrb, pacijentovu pokretljivost te kognitivne funkcije. ${ }^{27}$ Maksimalan broj bodova iznosi 35, a pacijente se svrstava u tri kategorije: visokog rizika za

\footnotetext{
** Skala je na engleskom jeziku slobodno dostupna na internetu, npr. https://consultgeri.org/try-this/general-assessment/issue-8.pdf

${ }^{* \star * \star}$ Skala je na engleskom jeziku slobodno dostupna na internetu, npr. http://www.hopkinsmedicine.org/institute_nursing/models_tools/Appendix\%20A_JHFRAT.pdf
}

pad (više od 13 bodova), umjerenog rizika za pad ( 6 do 13 bodova) te niskog rizika za pad (manje od 6 bodova). Procjena rizika od pada trebala bi se inicijalno provesti najkasnije osam sati od primitka u bolnicu, a reevaluacija svakodnevno ili čak i češće zbog promjena stanja pacijenta.

Prema komparativnoj studiji provedenoj u Južnoj Koreji, ${ }^{28}$ osjetljivost ove skale iznosila je od 62 do $69 \%$, specifičnost od 60 do $69,5 \%$, PPV od 30,1 do $33,6 \%$, a NPV od 86 do $88,6 \%$.

\section{ZAKLJUČAK}

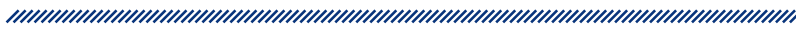

U ovom radu prikazali smo četiri najprimjenjivanije te ujedno u stručnoj literaturi najčešće istraživane skale za procjenu rizika od pada pacijenata u zdravstvenim ustanovama.

Prema metaanalizij ${ }^{29}$ koju je izradila skupina autora iz Španjolske, od tri analizirane skale (Morseova, STRATIFY i Hendrich II.) kao najpouzdanija i najpreciznija za upotrebu u akutno bolesnih hospitaliziranih odraslih pacijenata pokazuje se skala STRATIFY. Druga američka studija ${ }^{30}$ koja je uspoređivala Morseovu skalu i skalu STRATIFY osjetljivijom je procijenila Morseovu skalu, a slične rezultate dobili su i istraživači iz Južne Koreje, ${ }^{28}$ koji su najveću prediktivnu vrijednost za identificiranje pacijenata u kojih postoji visoki rizik od pada dobili upotrebom Morseove ljestvice.

Razlog različitosti rezultata navedenih studija jest taj što nijedna skala ne obuhvaća apsolutno sve rizične faktore koji utječu na povećani rizik od pada. Osim toga, na procjenu rizika od pada uz pomoć neke od skala utječu dobne karakteristike pacijenata (osjetljivost skala u procjeni rizika različita je kod pedijatrijske u odnosu na gerijatrijsku populaciju), tip osnovne bolesti zbog koje su pacijenti hospitalizirani (iste skale pokazuju različitu osjetljivost među bolničkim odjelima) te vrsta ustanove za pružanje zdravstvene njege (razlika u rezultatima skala u bolnicama za zbrinjavanje akutno oboljelih, bolnicama za produljeno liječenje, ustanovama za rehabilitaciju, ustanovama za palijativnu skrb ili domovima za starije i nemoćne osobe). Sve navedeno upućuje na to da je pri izboru idealne skale za procjenu rizika od pada potrebno u obzir uzeti specifične karakteristike populacije kojoj se pruža skrb. 


\section{LITERATURA}

1. Agencija za kvalitetu i akreditaciju u zdravstvu i socijalnoj skrb. Izvješće o pokazateljima sigurnosti pacijenta za 2014. Mesarić J, Hadžić Kostrenčić C, Šim D, ur.. Zagreb: Agencija za kvalitetu i akreditaciju u zdravstvu i socijalnoj skrb; 2015.

2. Agency for Healthcare Research and Quality. Patient Safety and Quality: An Evidence-Based Handbook for Nurses. Hughes RG, editor. Rockville: AHRQ Publication; 2008.

3. Hitcho EB. Characteristics and circumstances of falls in a hospital setting. Journal of General Internal Medicine. 2004; 19(7): 732-739.

4. Titler M. Cost of hospital care for elderly at risk of falling. Nursing Economics. 2005; 23(6): 290.

5. Fiesta J. Liability for falls. Nursing Management. 1988; 29(3): 24.

6. The National Patient Safety Agency. Slips, trips and falls in hospital. London:; 2007.

7. Perell KL, Nelson A, Goldman RL, Luther SL, Prieto-Lewis N, Rubenstein LZ. Fall risk assessment measures: an analytic review. The Journals of Gerontology Series A: Biological Sciences and Medical Sciences. 2001; 56(12): 761-766.

8. Dykes PC, Carroll DL, Hurley AC, Benoit A, Middleton B. Why do patients in acute care hospitals fall? Can falls be prevented? The Journal of Nursing Administration. 2009; 39(6): 299.

9. Vassallo M, Rachel S, Sharma JC, Allen S. A Comparative Study of the Use of Four Fall Risk Assessment Tools on Acute Medical Wards. Journal of the American Geriatrics Society. 2005; 53(6): 1034-1038.

10. Oliver, D., Daly, F., Martin, F. C., McMurdo, M. E. Risk factors and risk assessment tools for falls in hospital in-patients: a systematic review. Age and ageing. 2004; 33(2), 122-130.

11. Morse JM, Morse RM, Tylko SJ. Development of a scale to identify the fall-prone patient. Canadian Journal on Aging / La Revue canadienne du vieillissement. 1989; 8(04): 366-377.

12. Oliver D, Britton M, Seed P, Martin F, Hooper A. Development and evaluation of evidence based risk assessment tool (STRATIFY) to predict which elderly inpatients will fall: case-control and cohort studies. BMJ. 1997; 315(7115): 1049-1053.

13. Hendrich A, Bender PS, Nyhuis A. Validation of the Hendrich II Fall Risk Model: a large concurrent case/control study of hospitalized patients. Applied Nursing Research. 2003; 16(1): 9-21.

14. Poe SS, Cvach MM, Gartrell DG, Radzik BR, Joy TL. An Evidence-based Approach to Fall Risk Assessment, Prevention, and Management. Journal of Nursing Care Quality. 2005; 20(2): 107-116.

15. Razmus, I., Davis, D. The epidemiology of falls in hospitalized children. Pediatric nursing. 2012; 38(1), 31.
16. Eagle J, Salama S, Whitman D, Evans LA, Ho E, Olde J. Comparison of three instruments in predicting accidental falls in selected in-patients in a general teaching hospital. Journal of Gerontological Nursing. 199; 25(7): 40-45.

17. Schwendimann R, De Geest S, Milisen K. Evaluation of the Morse Fall Scale in hospitalised patients. Age and Ageing. 2006; 35(3): 311-313.

18. Oliver D, Papaioannou A, Giangregorio L, Thabane L, Reizgys $\mathrm{K}$, Foster $\mathrm{G}$. A systematic review and meta-analysis of studies using the STRATIFY tool for prediction of falls in hospital patients: how well does it work? Age and Ageing. 2008; 37(6): 621-627.

19. Costa-Dias MJMd, Ferreira PL. Fall risk assessment tools. Revista de Enfermagem Referência. 2014; IV(2): 153-161.

20. Department of Human Services, State of Victoria. Minimising the Risk of Falls \& Fall-related Injuries: Guidelines for Acute, Sub-acute and Residential Care Settings. 2004. Dostupno na: https://www.mnhospitals.org/Portals/0/Documents/ptsafety/falls/tools.pdf (pristupljeno 27. svibnja 2017.).

21. Hendrich A. Predicting patient falls. The American Journal of Nursing. 2007; 107(11): 50-58.

22. de Jong MR, Van der Elst M, Hartholt KA. Drug-related falls in older patients: implicated drugs, consequences, and possible prevention strategies. Therapeutic Advances in Drug Safety. 2013; 4(4): 147-154.

23. Hartikainen S, Lönnroos E. Use of sedatives and hypnotics, antidepressants and benzodiazepines in older people significantly increases their risk of falls. EvidenceBased Medicine. 2010; 15(2): 59.

24. Hendrich A, Bender PS, Nyhuis A. Validation of the Hendrich II Fall Risk Model: a large concurrent case/control study of hospitalized patients. Applied Nursing Research. 2003; 16(1): 9-21.

25. Kim EANK, Mordiffi SZ, Bee WH, Devi K, Evans D. Evaluation of three fall-risk assessment tools in an acute care setting. Journal of Advanced Nursing. 2007;60(4): 427-435.

26. Ivziku $D$, Matarese $M$, Pedone $C$. Predictive validity of the Hendrich fall risk model II in an. International Journal of Nursing Studies. 2011; 48(4): 468-474.

27. Poe SS, Cvach MM, Gartrell DG, Radzik BR, Joy TL. An Evidence-based Approach to Fall Risk Assessment, Prevention, and Management. Journal of Nursing Care Quality. 2005; 20(2): 107-116.

28. Kim KS. A comparative study on the validity of fall risk assessment scales in Korean hospitals. Asian Nursing Research. 2011; 5(1): 28-37.

29. Aranda-Gallardo M, Morales-Asencio JM, Canca-Sanchez JC, Barrero-Sojo S. Instruments for assessing the risk of falls in acute hospitalized patients: a systematic review and meta-analysis. BMC Health Services Research. 2013; 13(1): 122.

30. Harrington L. Meta-analysis of fall-risk tools in hospitalized adults. Journal of Nursing Administration. 2010; 40(11): 483-488. 


\section{REVIEW OF FALL RISK ASSESSMENT SCALES}

1 Roberto Licul

1 Tatjana Matteoni

1 Martina Močenić

1 General hospital Pula, Pula

\section{Abstract}

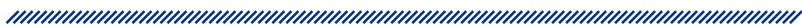

Patient falls in a hospital setting are adverse events in health care institution and pose as one of indicators of patient safety and quality indicators when it comes to the accreditation system. About one third of all falls cause some form of injury to the patient, and directly contribute to the lower healthcare quality level, inducing thereby also a variety of mental and somatic symptoms experienced by the patient. Therefore, the necessity of preventing patient falls is an important duty of all healthcare professionals, especially nurses. One of the tools for assessing the risk of falls risk is a standardized fall risk assessment scale. This paper presents four such scales, as follows: the Morse Falls Scale, the STRATIFY Scale, the Hendrich II Scale and the Johns Hopkins Fall Risk Assessment Tool. Each of them has certain advantages and disadvantages, all of them preferably having as high sensitivity and specificity as possible. An ideal scale should be simple to use, accurate, not time-consuming and easily implementable into clinical practice without staff overload. A result provided by a scale is a numerical value, which assesses patients' risk of falling (low, medium, high ...); such a risk assessment should always be followed by the appropriate preventive measures.
Keywords: patient safety, fall assessment, in-hospital falls, healthcare quality 